\title{
A obrigatoriedade do diploma e a identidade jornalística no Brasil: um olhar pelas margens
}

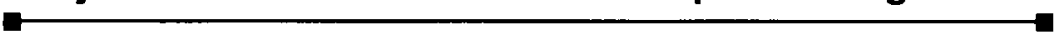

\author{
Afonso de Albuquerque *
}

\begin{abstract}
RESUMO
O artigo investiga o problema da delimitação das fronteiras que definem a prática legitima do jornalismo, tendo por referência a obra de Barbie Zelizer. Destaca, a este respeito, a sua proposição de que o profissionalismo se desenvolveu de forma incipiente no jornalismo e que a identidade jornalistica é construida com base em narrativas compartilhadas, através das quais os jornalistas se constituem como uma comunidade interpretativa autorizada. Visto que o modelo de Zelizer foi elaborado tendo por referência o jornalismo americano, é preciso verificar a sua aplicabilidade ao jornalismo de outros paises. $\mathrm{O}$ artigo faz isso em duas etapas. Na primeira, considera, de modo comparativo, o desenvolvimento do profissionalismo no jornalismo em diferentes paises da Europa Ocidental. Na segunda, discute o impacto que o decreto-lei $n^{\circ} 972$ de 17 de outubro de 1969, que regulamentou a profissão de jornalismo no Brasil, sobre o processo de construção de identidade dos jornalistas do pais.
\end{abstract}

Palavras-chave: jornalismo; identidade; diploma de jornalismo; comunidade interpretativa; Brasil

\section{ABSTRACT}

This article discusses Barbie Zelizer's analysis of the way journalists deal with the frontiers that define the legitimate practice of journalism. According to her, professionalism never played a significant role in journalism; instead it is by their sharing of narratives that journalists build a common identity and constitute themselves as an authorized interpretative community. Since the model proposed by Zelizer refers to the American journalism, it is necessary to check its applicability to journalism in other countries. This article presents then a comparative analysis of the development of professionalism in journalism in different Western Europe countries. Then it discusses the case of Brazil where particularly the impact and the way that the Decree-Law $n^{\circ} 972$ (October 17, 1969) regulated the profession of journalists in Brazil, has influenced since then the identity building of Brazilian journalists.

Key words: jornalism; identity; diploma of jornalism; interpretative community; Brazil

\footnotetext{
* Doutor em Comunicação e Cultura pela UFRJ (1996), professor do Programa de Pós-Craduação em Comunicação e coordenador do curso de graduação em Estudos de Midia da UFF. Seus temas de pesquisa incluem a construção da autoridade jornalistica no Brasil e o modelo brasileiro de propaganda politica na televisão.
} 
"Diogo Mainardi é, na feliz expressão de Luís Nassif, um parajornalista. Um dos muitos revelados nestes seis meses de crise. Ouviram falar de Carlos Lacerda e imaginaram que basta indignação e nenhum senso de responsabilidade para ganhar o respeito dos leitores. Seus colegas na direção de Veja ofereceramlhe uma isca e ele, faminto de reconhecimento, a abocanhou com voracidade" (Dines, 2005).

A afirmação, feita por Alberto Dines, no final de 2005, foi motivada por uma coluna na qual Mainardi denunciou que as redações jornalísticas estavam repletas de defensores do presidente Lula, e nomeou alguns deles, intitulando o seu gesto "macartismo mainardiano". A história é interessante por si só, mas o nosso interesse se prende a um aspecto muito particular do texto de Dines: o uso do rótulo "parajornalista" para qualificar o seu adversário chama a atenção para a importância que tem a delimitação das fronteiras que definem a prática legítima do jornalismo.

Tal questão constitui o tema fundamental deste artigo, que se divide em três partes. A primeira tem como objetivo discutir a questão da delimitação das fronteiras da prática profissional do jornalismo tal como ela foi desenvolvida por Barbie Zelizer, principalmente no seu livro Covering the Body. Em linhas gerais, o argumento da autora é que o jornalismo constitui um campo profissional pouco estruturado, especialmente se comparado ao que ocorre nas profissões liberais clássicas: direito e medicina. As taxas de sindicalização entre os jornalistas são bastante modestas, quase não há códigos de ética e de conduta profissional e, quando eles existem, têm pouca influência efetiva sobre os profissionais e não há necessidade de formação específica para exercer a profissão (1992: 6). Desta forma, ela acredita, o conceito de profissionalismo não proporciona o melhor ponto de partida para a análise do jornalismo. Zelizer propõe, então, um enfoque alternativo, estruturado em torno da noção de autoridade jornalística. Tal abordagem privilegia a dimensão cultural do fenômeno jornalístico, diferentemente da análise focada no profissionalismo, cujo caráter é fundamentalmente sociológico. $\mathrm{O}$ argumento da autora é que os jornalistas constituem uma comunidade interpretativa, que se constitui e se reconstrói através de narrativas que são compartilhadas pelos seus membros.

Naturalmente, devemos levar em conta que Zelizer elabora suas considerações a partir do jornalismo americano, e que este apresenta características muito particulares, as quais o distinguem profundamente do jornalismo praticado na maioria dos outros países (Albuquerque, 2005). A despeito disso, suas observações sobre o profissionalismo parecem ser pertinentes para um grande número de países, incluindo alguns em que o 
jornalismo se estrutura de acordo com uma lógica totalmente diversa da que vigora nos Estados Unidos. Esta discussão será desenvolvida na segunda parte deste artigo.

O caso do Brasil parece de algum modo diferir da regra geral, visto que desde 1969 vigora a exigência legal do diploma especifico para o exercício profissional do jornalismo. Mas o que isso quer dizer? Seria o profissionalismo um traço mais marcante do jornalismo brasileiro do que em outros paises, ou a obrigatoriedade do diploma teria outro significado? A terceira parte do artigo lida com essas questões e discute a aplicabilidade das considerações tecidas por Zelizer à realidade brasileira.

\section{Jornalismo e Autoridade Interpretativa: a Perspectiva de Barbie Zelizer}

A obra de Barbie Zelizer deve ser entendida no contexto da renovação dos estudos sobre o jornalismo, que se iniciou na década de 1980 e se aprofundou na segunda metade da década seguinte. A principal característica dos novos estudos foi concentrar o seu foco de análise nas especificidades do fenômeno jornalistico, ao invés de lidar com ele como meramente uma forma particular de aplicação de fenômenos sociais genéricos (o discurso, o profissionalismo, o processo de construção social da realidade etc). Tal processo não se limitou apenas ao plano do debate acadêmico propriamente dito, mas se traduziu também no surgimento de novos fóruns para o debate, tais como periódicos especializados - Journalism, Journalism Studies - e um novo grupo de trabalho (interest group) da International Communication Association, criado em 2004.

Esse processo de institucionalização da pesquisa sobre o jornalismo não pode ser entendido como uma evidência direta de uma suposta consolidação do jornalismo como campo da prática profissional. Bem ao contrário, foi antes o espectro da crise, o abalo das certezas sobre o jornalismo - que, nos Estados Unidos, haviam atingido o seu ápice entre as décadas de 1950 e 1980, naquilo que Hallin (1996) qualificou como "consenso da guerra fria" - que fomentou o interesse acadêmico pelo tema'. A globalização econômica, a formação de gigantescos conglomerados multimidiáticos e as crescentes pressões comerciais sobre o jornalismo que resultam daí, a explosão da tecnologia digital, a crescente interpenetração entre o jornalismo e outros formatos comunicativos (evidente, por exemplo, nos portais da internet), a nova conjuntura internacional que se estabeleceu após os atentados de 11 de setembro de 2001 e os embates em torno do multiculturalismo são alguns fatores que ajudam a explicar a crescente ansiedade que se desenvolveu em

\footnotetext{
- De modo análogo, a sociologia dá conta de um olhar acadêmico sobre a sociedade que se constituiu a partir da experiência da sua crise, no final do século $X I X$ associada ao advento do capitalismo industrial e da urbanização acelerada.
} 
torno do jornalismo no mundo atual. Por um lado, multiplicam-se as dúvidas sobre o futuro do jornalismo tradicional e das funções classicamente atribuídas aos jornalistas profissionais; por outro lado, pipocam modelos alternativos de jornalismo - por exemplo, o jornalismo público, o Centro de Mídia Independente (Indymedia), o jornalista-cidadão do Ohmy News, na Coréia do Sul - os quais, como regra geral, se valem das potencialidades comunicativas dos meios digitais. Some-se a isto a concorrência proporcionada por novos formatos comunicativos, como os blogs, os quais têm, por vezes, se constituído em importantes fontes de informação em situações de crise, tais como conflitos armados e catástrofes naturais.

Em conformidade com essas tendências, Zelizer concentra a sua atenção no processo pelo qual os jornalistas demarcam as fronteiras de sua profissão, em referência a outros agentes sociais. O seu objetivo não é identificar as características essenciais do jornalismo - o Santo Graal dos autores que, no Brasil, se agrupam em torno do rótulo de "teoria do jornalismo". Segundo ela, as definições de jornalismo oriundas do campo profissional dão conta apenas de uma fração muito restrita da atividade jornalística - o universo das hard news - e reproduz concepções muito limitadas oriundas das salas de redação (2004: 6-7). Não é, igualmente, apontar os traços que fazem do jornalismo um fenômeno social específico, à moda da sociologia do jornalismo. Embora esta linha de investigação tenha muito a contribuir para o entendimento do modo de organização da produção da notícia, ela não parece tão adequada para lidar com o problema da construção da identidade profissional entre os jornalistas. Em particular, as ferramentas tomadas de empréstimo à sociologia das profissões - moldadas a partir do exemplo das profissões liberais clássicas, direito e medicina - não funcionam bem quando aplicadas à análise do jornalismo. Segundo ela, o uso dessas categorias como base da análise levaria, por certo, a uma definição dos jornalistas como profissionais mal-sucedidos, visto que faltam ao jornalismo algumas características fundamentais às formas institucionalizadas de profissionalismo, tais como treinamento especializado, códigos de ética e conduta, políticas de licenciamento etc (1992a: 7). Por esta razão, a autora se apóia em uma perspectiva teórica mais flexível, que enfatiza a dimensão cultural do fenômeno jornalístico e, em particular, o modo como os jornalistas buscam se legitimar como intérpretes autorizados da realidade.

Para tal, Zelizer recorre ao conceito de "comunidades interpretativas", tomado de empréstimo à teoria literária de Stanley Fish (1980). Segundo este autor, a busca pelo significado inerente aos textos é uma tarefa fadada ao fracasso: é, antes, no processo de interpretação que este significado deve ser procurado. $\mathrm{O}$ ator fundamental deste processo não é o leitor individual, mas as comunidades interpretativas, que estabelecem os parâmetros que definem quais são as interpretações autorizadas de um texto, e quais leituras 
são aberrantes. De acordo com Zelizer, os jornalistas formam um tipo de comunidade interpretativa, que tem na questão da autoridade jornalística definida pela autora como "a capacidade dos jornalistas de se promoverem como porta-vozes autorizados e criveis dos eventos da "vida real" (1992a: 8) - o seu eixo central.

Tais comunidades não se estruturam fundamentalmente por referência a procedimentos e recursos formais como manuais ou códigos de profissionalismo, mas através de narrativas compartilhadas, em torno das quais eles constituem uma memória coletiva sobre o jornalismo. Os relatos sobre a atuação dos jornalistas na cobertura do assassinato de Kennedy (Zelizer, 1992a), por exemplo, ajudaram a legitimar o telejornalismo, que até então tinha um status bastante marginal, e permitiu aos jornalistas reivindicar algum tipo de autoridade histórica sobre o tema (o que, naturalmente, os pôs em rota de colisão com os historiadores profissionais). Do mesmo modo, as narrativas sobre a cobertura da primeira Guerra do Golfo (de 1991) pela Cable News Network (CNN) ajudaram a legitimar um novo modelo de jornalismo, em tempo real e amparado em novas tecnologias da comunicação, baseadas no uso de satélites, e levar para o primeiro time do jornalismo uma empresa que por muito tempo fora considerada uma organização de segunda categoria, vilipendiada por alguns como "Chicken Noddle Network" (Zelizer, 1992b).

Resta saber se as observações sobre o caráter da atividade jornalística se referem exclusivamente ao contexto americano ou se tem uma aplicabilidade mais geral. Esta questão será discutida a seguir.

\section{Jornalismo e Profissionalismo: uma Perspectiva Comparada}

Sabemos que nos Estados Unidos se desenvolveu um modelo bastante original de jornalismo, baseado em uma sólida tradição de liberdade de expressão - cuja expressão máxima é a Primeira Emenda da Constituição estruturado em torno do valor da objetividade jornalística e ancorado no mercado, particularmente em verbas oriundas da publicidade (Blanchard, 1986; Schudson, 1978; Schudson, 1994; Schudson, 1992). Diante disso, é lícito perguntar o quanto as observações de Zelizer sobre os limites do profissionalismo no jornalismo se aplicam a outros países.

A resposta para essa pergunta não é simples. Em alguns países, a lógica do profissionalismo parece ter penetrado o jornalismo de modo muito mais profundo do que nos Estados Unidos. É este o caso dos paises cujo sistema midiático é classificado por Hallin e Mancini através do rótulo "democrático corporatista": os países da região central e setentrional da Europa Ocidental. Incluem-se aí os países escandinavos, a Alemanha, a Áustria, a Holanda e, um pouco menos claramente, a Bélgica. Neles, as associações profissionais se desenvolveram pioneiramente e se tornaram 
bastante influentes, não apenas no que concerne à sua representatividade junto aos jornalistas (a taxa de membros delas varia de $50 \%$ à quase totalidade dos jornalistas), mas à sua capacidade de garantir aos jornalistas um certo grau de autonomia frente ao Estado e às organizações jornalísticas. A existência de cursos universitários de jornalismo ajudou a cimentar a identidade jornalística, embora eles tenham surgido muito depois das associações profissionais e dos sistemas de auto-regulamentação que eles criaram (2004: 170-178).

$\mathrm{Na}$ maior parte dos países, contudo, o desenvolvimento do profissionalismo no jornalismo se deu de modo bem menos efetivo. Isso é verdade mesmo para o Reino Unido, o que pode surpreender quando se considera que o país é tomado por muitos, no Brasil, como um modelo de jornalismo de qualidade. É preciso deixar claro, de início, que muitos analistas sustentam que não há no Reino Unido um, mas três sistemas jornalísticos organizados segundo princípios diversos: a imprensa "de qualidade", o modelo de jornalismo como serviço público, dominante no rádio e na televisão, cujo principal referencial é o jornalismo da BBC, e o jornalismo popular, baseado nos tablóides (Hallin e Mancini, 2004: 12). Köcher (1986) observou que os jornalistas britânicos eram mais jovens e tinham consideravelmente menos educação formal do que seus colegas alemães. O ensino superior em jornalismo se iniciou tardiamente no país, em parte porque durante muito tempo prevaleceu a opinião de que o tema era demasiado técnico e carecia de rigor acadêmico para justificar um curso universitário (Zelizer, 2004). A situação começou a mudar significativamente apenas a partir da década de 1990 , quando começaram a surgir os primeiros cursos superiores de jornalismo até então, havia apenas cursos de pós-graduação em jornalismo (Burgh, 2003).

Também na França, o desenvolvimento de um ethos profissional no jornalismo se fez de maneira bastante modesta. Historicamente, o jornalismo se desenvolveu no país à sombra da literatura e da política (Chalaby, 1996), de modo que não existiram as melhores condições para o desenvolvimento de uma cultura profissional independente. É bem verdade que, desde 1935, vigora na França um estatuto profissional do jornalismo, definido por lei, e existe uma carteira de identidade profissional, fornecida pela Comissão da Carteira de Identidade dos Jornalistas Profissionais (CCIJP), composta de maneira paritária por representantes dos patrões e dos empregados. Contudo, ela não constitui um pré-requisito para o exercício da profissão, e seus critérios de classificação são freqüentemente contestados judicialmente (Ruellan, 2004a). Em 1990, 7 em cada 10 portadores de carteira profissional tinham nível superior mas apenas $20 \%$ dentre eles tinham formação específica em jornalismo. A exigência do diploma específico jamais foi cogitada como um pré-requisito indispensável para o exercício do jornalismo, o que, segundo Neveu, se explica "pela dimensão mimética de certas aprendizagens do 
jornalismo" (2005: 27). Refletindo sobre a natureza da organização do jornalismo no seu pais, Ruellan o define como dotado de uma "vocação mestiça" (2004 b: 11).

Em Portugal, o desenvolvimento do jornalismo foi retardado pela ditadura salazarista, que durou quatro décadas e estabeleceu um regime de censura sistemática à imprensa, até a derrubada do regime, com a Revolução dos Cravos em 1974. A instabilidade política que se seguiu, a ausência de condições econômicas do mercado local para sustentar uma imprensa mais sólida levaram Agee e Traquina (s.d.), no final da década de 1980, a caracterizarem o projeto de desenvolvimento do jornalismo português como um "Quarto Poder frustrado". Segundo Hallin e Mancini (2004), Portugal assim como outros países mediterrâneos, tais como a Itália, a Espanha e a Grécia - apresenta um padrão de forte paralelismo dos meios de comunicação em relação a forças políticas específicas, um baixo nivel de autonomia dos jornalistas frente às forças políticas e econômicas, organizações representativas que se dividem em torno das clivagens politicas da sociedade. Tal como na França e na Itália - no caso deste último país, os jornalistas devem pertencer à Ordem dos Jornalistas para exercer a sua profissão - 0 exercício do jornalismo é regulamentado pelo Estado. No entender dos autores, tal caracteristica, longe de ser um indice de autonomia profissional do jornalismo, aponta para uma relação de forte dependência em relação ao Estado. Os cursos superiores em jornalismo no país se constituíram na década de 1990 e se expandiram significativamente a partir de 2000 (Pinto, 2004).

Embora o conjunto de casos analisados aqui esteja longe de ser representativo em relação à diversidade das formas que o problema do profissionalismo assume no jornalismo em âmbito mundial, ele nos permite avançar algumas conclusões provisórias. Por um lado, parece claro que a tradição de investigação sobre o profissionalismo se aplica aos estudos sobre o jornalismo apenas em circunstâncias bastante particulares, como as que se encontram nos países escandinavos, por exemplo. Tal constatação legitima a necessidade de se buscar outros referenciais teóricos, que sejam capazes de lidar com a questão da identidade jornalística de modo mais flexivel, que atente para os mecanismos informais através dos quais ela é construída. O modelo analítico proposto por Zelizer constitui apenas uma das alternativas possíveis para enfrentar o problema e, naturalmente, não se deve esperar que ele tenha aplicabilidade universal. Contudo, é plausivel que questões desenvolvidas tendo em vista o jornalismo americano venham a ser úteis para dar conta de questões que advêm da sua influência sobre o modelo de jornalismo de outros países. Na terceira parte deste artigo examinaremos a aplicabilidade do modelo analítico de Zelizer ao caso do jornalismo brasileiro, tendo em vista, em particular, a influência precoce que o modelo americano de 
jornalismo exerceu no país e a questão da obrigatoriedade do diploma específico para o exercício da profissão.

\section{A Identidade Profissional e o Diploma Específico: o Jornalismo no Brasil}

A aplicação do modelo analítico desenvolvido por Barbie Zelizer ao jornalismo brasileiro apresenta desafios únicos e instigantes. Por um lado, a influência do modelo americano sobre o jornalismo brasileiro tem sido bastante expressiva por mais de cinco décadas; há muito mais tempo do que aconteceu em outros países, portanto. Assim, é plausível que um modelo cunhado para a análise da realidade do jornalismo americano possa se demonstrar útil para a análise do caso brasileiro. Por outro lado, por "influência" não se entende a pura e simples adoção do modelo americano ou de aspectos particulares da sua retórica e/ou suas práticas profissionais. Trata-se, antes, de um esforço de apropriação do modelo americano, isto é, de sua adaptação tendo em vista as particularidades da sociedade local (Albuquerque, 2005). Esta parte do artigo busca explorar, à luz do modelo analítico proposto por Zelizer, a importância que a exigência legal do diploma específico para o exercício do jornalismo, estabelecida por decreto em 1969, pela Junta Militar que então governava o país, desempenhou no processo de construção da identidade profissional no campo.

De acordo com a narrativa corrente, na década de 1950, um pequeno grupo de jornalistas sediados no Diário Carioca "importou", dos Estados Unidos, um conjunto de técnicas e valores jornalísticos (o lead, a objetividade jornalística) e, dessa forma, deu origem ao jornalismo moderno no Brasil. Ao enfocar a ação modelar de um grupo de pioneiros na construção de um novo modelo de jornalismo no Brasil, essa narrativa se caracteriza antes como tendo um caráter mítico do que histórico. Ele diz muito pouco sobre as razões que permitiram ao novo modelo criar raizes e se difundir no país, além de tratar a transformação do jornalismo brasileiro nos termos de uma mera transferência de modelos de um país para outro. Por outro lado, a transformação do jornalismo brasileiro tem sido freqüentemente descrita como um fenômeno de caráter moral, que permitiu a jornalistas profissionais, comprometidos com o interesse público na difusão da informação, substituir os jornalistas "boêmios" e "picaretas" que predominavam nas redações (Abreu, 1998. Ribeiro, 2003).

Tais características não tornam este relato menos interessante para os nossos fins. Ao contrário, a força com que ele se difundiu entre os jornalistas - a tal ponto que ele se tornou a narrativa padrão sobre o advento da modernidade do jornalismo no discurso dos profissionais e das escolas de jornalismo - faz dele um exemplo bastante evidente do modo como, também 
no Brasil, narrativas compartilhadas parecem ter desempenhado um papel fundamental na construção do jornalismo como comunidade interpretativa no Brasil. Contudo, a força que este relato exerceu (e ainda exerce) no modo como os jornalistas brasileiros constroem a sua identidade profissional contrasta com o relativo esvaziamento do papel desempenhado por outros relatos, concorrentes ou complementares. Não se trata de negar que outras narrativas tenham sido apresentadas - podemos lembrar, por exemplo, dos relatos sobre o "jornalismo alternativo" que existiu durante o regime militar ${ }^{2}$ e da modernização capitalista promovida pelo jornal Folha de S. Paulo na década de $1980^{3}$ - mas apenas de reconhecer que nenhuma deles chegou a desempenhar um papel remotamente comparável ao "mito dos anos 50" no processo de construção da identidade jornalistica brasileira.

$\mathrm{O}$ fato de narrativas referentes a acontecimentos de cinco décadas atrás terem permanecido como o referencial incontestado da construção da identidade jornalistica no Brasil é algo que merece reflexão. Por certo, mitos de origem têm a sua importância, mas o que temos aqui é algo mais: o apagamento da história, a minimização da importância de tudo aquilo que se seguiu ao ato fundador. Tudo se passa como se o jornalismo moderno tivesse sido criado no passado e, desde então, nada o tivesse abalado, nada pudesse se acrescentar a ele. Como isso pode ocorrer? Trata-se de uma questão muito complexa para que a possamos explorar em profundidade neste artigo. Por este motivo, limitamos-nos a discutir um possível fator: a obrigatoriedade do diploma específico para o exercicio do jornalismo, estabelecida por decretolei pela Junta Militar que governou o país durante dois meses, em $1969^{4}$.

O decreto-lei $n^{\circ} 972$, de 17 de outubro de 1969, regulamentou a profissão de jornalista em diferentes aspectos. Além de exigir o diploma em curso superior de jornalismo para o exercício da profissão, há outros traços do decreto-lei que merecem ser mencionados. Em primeiro lugar, o decreto não traz uma definição unificada acerca do que constituiria a atividade jornalística. Ao invés disso, ele opta, no seu artigo segundo, por uma listagem

\footnotetext{
${ }^{2}$ As narrativas sobre o jornalismo alternativo desempenham um papel muito importante na construção da imagem romântica do jornalista brasileiro como cäo de guarda da sociedade, fiel a ponto de preservar o seu compromisso mesmo nas condicöes mais adversas. Eventualmente, alguns relatos se valem do exemplo do jornalismo alternativo para sugerir que a imprensa como um todo enfrentou a censura e se recusou a colaborar com o regime, o que por certo näo é verdade (cf. Smith, 2000). O valor exemplar deste tipo de relato é, contudo, limitado por dois fatores fundamentais: a excepcionalidade do periodo em questão e o caráter precário, artesanal da grande maioria dos veículos do jornalismo alternativo, que em nada favoreceram a continuidade do modelo (ver a respeito Kucinski, 1991, e Braga, 1991).

${ }^{3}$ Os relatos sobre a transformaçäo do jornalismo durante a década de 1980 se centram sobretudo no caso do jornal Folha de S. Paulo, e da reforma que ele promoveu entre 1984 e 1987 (0 "Projeto Folha"). Esses relatos dão conta de um curioso exemplo de como a ausência de distanciamento critico pode levar o discurso acadêmico sobre um objeto a reproduzir com fidelidade o discurso que este objeto enuncia acerca de si mesmo. Não deixa de ser interessante o fato de que uma das principais referências do discurso acadêmico sobre a Folha nos anos 1980 (Silva, 1988; Silva, 1991) foi um dos coordenadores do "Projeto Folha". No que diz respeito à construçāo da identidade jornalistica, contudo, este relato teve influência limitada, até porque ele centra o seu foco na empresa jornalistica (e não no jornalista individual) como agente da mudança.

- A Junta era integrada pelos três ministros das Forças Armadas: Aurélio de Lima Tavares (Exército), Augusto Rademaker (Marinha de Guerra) e Márcio de Sousa e Mello (Aeronáutica Militar).
} 
extensiva de atividades, bastante distintas entre si: incluem-se aí atividades como a reportagem, a redação, a coleta de informações, comentários, crônicas, produção gráfica, elaboração de desenhos artísticos ou técnicos de caráter jornalístico, revisão de textos, organização de arquivos jornalísticos, a pesquisa realizada nesses arquivos para a elaboração de notícias e o ensino de técnica de jornalismo. Diante de um conjunto tão extenso e diversificado de atividades, pode-se dizer que, na prática o decreto-lei define como "atividade jornalística" o conjunto de atividades exercidas no âmbito das empresas jornalísticas.

Resta saber como o decreto-lei define as empresas jornalísticas. No artigo terceiro, ele apresenta a empresa jornalística como “aquela que tenha como atividade a edição de jornal ou revista, ou a distribuição de noticiário, com funcionamento efetivo, idoneidade financeira e registro legal". Tal definição é, contudo, consideravelmente estendida no primeiro parágrafo do artigo, uma vez que este define que seções ou serviços de empresas de radiodifusão, televisão, divulgação cinematográfica ou agências de publicidade nas quais sejam exercidas as atividades listadas no artigo segundo devem ser equiparadas a uma empresa jornalística.

Um terceiro aspecto que deve ser mencionado refere-se ao papel que o decreto-lei reserva ao sindicato, de denunciar às autoridades competentes as irregularidades cometidas no exercício da profissão. Este aspecto se liga a um quarto, que transparece nitidamente ao longo de todo o 82 texto do decreto-lei, relativo à intenção do governo de estabelecer um rígido controle sobre a atividade jornalística. $O$ diploma se perfila a outras exigências que o decreto-lei estabelece para o exercício da profissão, tais como prova de nacionalidade brasileira ${ }^{5}$ e folha corrida. Além disso, o decreto estabelecia, no seu artigo 11, que haveria, no primeiro ano de vigência do decreto-lei, uma revisão do registro profissional de jornalistas, e que seriam cancelados aqueles "viciados por irregularidade insanável".

Em outubro de 2001, a Juíza Carla Rister suspendeu provisoriamente a obrigatoriedade do diploma, atendendo a uma demanda apresentada pelo Ministério Público. Depois de idas e vindas, a obrigatoriedade foi restabelecida quatro anos depois, em outubro de 2005. Durante este período, a obrigatoriedade do diploma foi objeto de um amplo debate, que envolveu jornalistas e outros agentes sociais. Um dos pontos sensiveis do debate disse respeito à origem ditatorial do decreto-lei $n^{\circ} 972$. Afinal, o decreto foi outorgado no período mais sombrio do regime militar, em um período em que o Congresso Nacional havia sido fechado e foi amparado pela legislação autoritária do Ato Institucional $n^{0} 5^{6}$. Alguns defensores da obrigatoriedade

\footnotetext{
5 A importância que esse item adquire como instrumento de controle da imprensa foi exemplificada, na década de 1950, pelos ataques movidos por Carlos Lacerda contra o jornal Última Hora, cujo proprietário, Samuel Wainer, era acusado de não ter nascido no Brasil, e sim na Bessarábia (Wainer, 2000; Laurenza, 1998).
} 
do diploma sustentam que não obstante o caráter autoritário do processo, a exigência do diploma atendeu a uma demanda histórica da categoria jornalística e, que, portanto, a sua permanência se justificaria em um regime democrático. Esta tem sido, por exemplo, a posição da Federação Nacional dos Jornalistas (FENAJ) em diversos documentos sobre o assunto (cf. Fortes e Albuquerque, 2004).

É plausível que a regulamentação da obrigatoriedade do diploma tenha vindo ao encontro dos interesses dos sindicatos de jornalistas. Isso não significa, porém, que este tenha sido um objetivo primordial dos formuladores do decreto-lei. De fato, não é muito sensato imaginar que um regime que perseguiu, torturou e matou sindicalistas e jornalistas ${ }^{7}$ demonstrasse algum tipo de sensibilidade frente às demandas históricas de uma organização sindical ${ }^{8}$. Por outro lado, seria muito mais provável supor que ele quisesse manipular essa demanda em proveito de seus próprios interesses.

Do ponto de vista do regime militar, a exigência do diploma específico parece ter estado ligada à intenção de estabelecer um mecanismo de controle sobre o processo de contratação de jornalistas pelas organizações noticiosas. Grassava, entre as autoridades do regime, a preocupação con relação à forte presença de comunistas dentre os jornalistas das salas de redação de inúmeros jornais9. Relata-se, por exemplo, que, diante da pressão do ministro da Justiça do governo do presidente Castelo Branco, Juracy Magalhães, para que demitisse os comunistas do seu jornal, Roberto Marinho respondeu afirmando que "dos meus comunistas cuido eu, na minha casa ninguém se mete" (Andrade, 2003: 35). Ao que tudo indica, na estratégia do regime, a exigência de diploma em curso superior de jornalismo constituiria um obstáculo para as redes de relações informais entre os jornalistas que facilitavam a contratação de comunistas. Esperava-se que a universidade ajudaria a formar jornalistas mais concentrados em questões "técnicas" do que politicas. Não é por acaso que o decreto-lei foi acompanhado pela reformulação curricular dos cursos de jornalismo, que deu origem aos cursos de Comunicação Social, contando também com as habilitações propaganda e relações públicas (Weber, 2000).

Uma das conseqüências do estabelecimento da obrigatoriedade legal do diploma para o exercício do jornalismo foi o aumento extraordinário do

\footnotetext{
- É digno de nota que o texto de abertura do decreto-lei 972 - "Os ministros da Marinha de Guerra, do Exército e da Aeronáutica Militar, usando das atribuiçōes que lhes confere o artigo $3^{\circ}$ do Ato Institucional $n^{\circ} 16$, de 14 de outubro de 1969 , combinado com o $\$ 1^{\circ}$ do artigo $2^{\circ}$ do Ato Institucional $n^{\circ} 5$, de 13 de dezembro de 1968, decretam:" - é usualmente excluído dos sítios dos sindicatos de jornalistas que o reproduzem a titulo de legislação sobre o jornalismo.

' O assassinato de Vladimir Herzog se deu no contexto de uma onda de repressão generalizada que levou diversos outros jornalistas a serem presos e torturados. Para um relato em primeira pessoa sobre 0 assunto, ver Markun, 2005.

${ }^{8} \mathrm{Em}$ seu livro sobre a FENAJ, Sá afirma que a regulamentação da profiss são é uma conquista da classe jornalística. Paradoxalmente, ela informa que a associação "não aceitou fazer parte do grupo de trabalho que iria apresentar o projeto de lei que regulamentou o Decreto-lei 972 . Critica-se a ABI por haver participado deste grupo" (1999: 158).

${ }^{q}$ Sobre a presença dos comunistas nas salas de redação, ver, por exemplo, Abramo, 1988, e Abreu, 2003.
} 
número de cursos superiores com habilitação em jornalismo. De acordo com Weber (2000: 168), o número de cursos de Comunicação registrados pulou de 20 em 1968 (um ano antes do decreto-lei), para $46 \mathrm{em} 1972$ e daí para $60 \mathrm{em}$ 1977. Os dados apresentados por José Milton dos Santos (em Medina, 1987: 78) são ainda mais dramáticos, pois dão conta de um aumento de 24 cursos em 1970, para 66 em 1972. Independentemente das diferenças quanto às cifras, nos dois casos torna-se evidente a associação entre a explosão do número de cursos superiores e a obrigatoriedade do diploma. É digno de nota que o número de cursos continuou aumentando nos anos que se seguiram, a tal ponto que, em 2005, apenas no município do Rio de Janeiro, 14 instituições de ensino superior ofereciam cursos de jornalismo; e, se considerarmos que algumas delas oferecem o curso em diferentes campi, temos, na prática, a oferta de 20 cursos de jornalismo.

Por sua vez, a explosão do número de cursos universitários no país levou a que, rapidamente, o número de jornalistas formados se tornasse muito superior ao de postos de trabalho disponíveis nas organizações jornalísticas. Deste modo, um grande número de jornalistas formados passou a exercer outros tipos de atividades ligadas ao campo da comunicação, tais como, por exemplo, serviços de assessoria de imprensa - o que motivou uma ácida disputa corporativa dos jornalistas com os profissionais de relações públicas, que viram nisso uma invasão do seu próprio mercado de trabalho (cf. Lopes e Vieira, 2004).

84 Do ponto de vista dos sindicatos de jornalistas, essa explosão do ensino superior em jornalismo trouxe vantagens evidentes: um maior número de graduados em jornalismo significava uma oportunidade para o crescimento do número de associados e os proventos decorrentes disso: aumento dos recursos e de prestígio do sindicato. Para os graduados que trabalhavam em outras áreas que não as organizações noticiosas, o sindicato se transformou em um referencial essencial da afirmação da sua identidade como jornalistas. Paralelamente, para os sindicatos de jornalistas tornou-se conveniente ampliar a definição do que constitui o campo de trabalho dos jornalistas, pois isto não apenas lhes permitia aumentar o número de associados como também lhes assegurava uma posição política altamente vantajosa: o de líder de uma cruzada corporativa. É importante destacar, a este respeito, que a enorme ampliação do mercado definido como jornalístico que se verificou a partir da década de 1970 encontra amparo no decreto-lei $n^{\circ} 972$, particularmente pelo primeiro parágrafo do artigo terceiro, que define como jornalísticas não apenas as atividades exercidas no âmbito das empresas noticiosas, mas também aquelas realizadas no âmbito de outros tipos de empresa que guardem analogia com elas.

Em resumo, o decreto-lei $\mathrm{n}^{\circ} 972$ teve um impacto significativo sobre o processo de construção da identidade jornalística por diferentes motivos: 
1. ao relacionar a identidade de jornalista à posse do diploma em curso de graduação específico, ele enfraqueceu os vínculos entre essa identidade e a prática jornalística concreta ${ }^{10}$;

2. ao caracterizar uma gama extremamente variada de atividades como sendo de natureza jornalística, abrangendo inclusive atividades realizadas no âmbito de organizações não-jornalisticas, ele esgarçou de tal forma o conceito de jornalismo que se tornou quase impossível estabelecer parâmetros de conduta comuns ao conjunto das atividades definidas como jornalísticas ";

3. este problema foi agravado pela proliferação de cursos universitários de jornalismo, a qual foi estimulada pelo decreto-lei $\mathrm{n}^{\circ}$ 972. O volume de graduados em jornalismo logo se tornou muito superior ao que as organizações jornalísticas stricto sensu poderiam absorver. Assim, um número crescente de profissionais passou a exercer atividades que, embora de natureza bastante diversa das realizadas no âmbito daquelas organizações, eram chanceladas por lei como tendo caráter jornalístico.

4. o estabelecimento de uma reserva de mercado legal serviu como fator de inibição de um papel mais ativo das associações profissionais no debate sobre a identidade profissional. Visto que o diploma permitia aos jornalistas reivindicar o monopólio legal do exercício de diversas atividades, tornou-se pouco interessante para as associações profissionais promover definições mais restritivas sobre o jornalismo, pois isso implicaria em marginalizar uma grande parcela dos associados. Deste modo, os sindicatos de jornalistas priorizaram os interesses corporativos da classe, ao invés de o papel de referencial do processo coletivo de construção da identidade jornalística.

\section{Conclusão}

Podemos, agora, retornar à nossa questão fundamental: em que medida o modelo analítico desenvolvido por Zelizer a partir do exemplo do

\footnotetext{
${ }^{10}$ Adghirni resume o problema de modo muito preciso: "A condição profissional, portanto, é determinada pela formação acadêmica e não pelo perfil do emprego. Desta forma, uma pessoa formada em jornalismo pela universidade será sempre jornalista, ainda que exerça outra profissão" (2004).

"Segundo Ettema e Classer (1998), o jornalismo americano (que serve de modelo explicito para o brasileiro) se fundamenta em valores que não são totalmente compativeis entre si. Por exemplo, ovalor da objetividade pressupōe uma atitude de desengajamento por parte do jornalista, enquanto o valor de cão de guarda enfatiza o seu compromisso na defesa dos interesses da sociedade. Dessa forma, os jornalistas se veriam obrigados a resolver na prática os seus dilemas éticos. A situação gerada pelo decreto-lei n 972 é bem mais complexa do que esta. A questão, aí, não se refere à ambigüidade de valores referentes a um mesmo objeto, mas à própria dispersão do objeto, que passa a designar atividades cuja natureza e compromisso ético diferem enormemente entre si (por exemplo, o trabalho em um jornal e na assessoria de imprensa). Novamente, citamos Adghirni para ilustrar os problemas derivam dai: "A mídia é alimentada pelas informaçōes fornecidas pelas fontes intermediárias que, no caso, são outros jornalistas. Trata-se de colegas de profissão, que freqüentaram Faculdades de Comunicação, têm habilitação em Jornalismo, registro profissional fornecido pelo Ministério do Trabalho e que agora se encontram 'do outro lado', formando um grande contingente de jornalistas/funcionários ou jornalistas/assessores de empresas privadas e de organizaçōes não-governamentais" (2004: 144).
} 
jornalismo americano é aplicável ao caso brasileiro? Vimos que a autora sugere que o profissionalismo não oferece o melhor ponto de partida para a análise do jornalismo e apresenta os conceitos de comunidade interpretativa e autoridade jornalística como alternativas teóricas a ele. Vimos também que, embora as observações da autora quanto ao profissionalismo não possam ser universalizadas - alguns países da Europa setentrional apresentam um grau considerável de profissionalismo - elas se aplicam a muitos países, entre os quais alguns que, historicamente têm servido de referência para o jornalismo brasileiro: Reino Unido, França e Portugal, por exemplo. Considerando que, a partir da década de 1950, o jornalismo americano tem servido de referencial privilegiado para o brasileiro, é justo perguntar o quanto, ou em que termos, o modelo analítico desenvolvido por Zelizer pode trazer luz para aspectos do modo como o jornalismo se desenvolveu no país.

Constatamos que uma narrativa tem dominado o processo de construção da identidade do jornalista brasileiro: o relato sobre a modernização do jornalismo brasileiro a partir da década de 1950. À primeira vista, isto poderia sugerir que o modelo de Zelizer se aplica plenamente à análise do caso brasileiro. Contudo, o fato de esta narrativa ter predominado tão absoluto por tanto tempo sugere que a resposta pode não ser tão simples. Ele sugere que narrativas rivais encontraram pouco espaço para se desenvolver no país. Assim, torna-se imperioso discutir por que isto teria ocorrido. Sugerimos que o estabelecimento da obrigatoriedade do diploma para o exercício profissional do jornalismo pode ser um fator importante para explicar o fenômeno. Duas questões derivam daí: seria a obrigatoriedade do diploma uma evidência do vigor do profissionalismo no jornalismo brasileiro? $\mathrm{E}$ de que maneira ela afetou o processo de construção da identidade jornalística no Brasil?

Com relação à primeira pergunta, a resposta é negativa. Conforme observam Hallin e Mancini, nem a formação específica em jornalismo, nem a regulamentação formal do jornalismo são critérios suficientes para caracterizar um alto nível de profissionalismo. Nos Estados Unidos, por exemplo, profissionais graduados em jornalismo são mais comuns nas organizações noticiosas menos prestigiosas que nas de maior prestígio; o fato de diploma específico ser muito mais comum entre os jornalistas espanhóis do que entre os alemães não significa que o nível de profissionalização seja maior no primeiro caso do que no segundo (bem ao contrário); na Itália, único caso da amostra analisada pelos autores em que a afiliação à Ordem dos Jornalistas é pré-requisito obrigatório para o exercício da profissão, o jornalismo tem um nível especialmente baixo de profissionalização (2004: 33-34).

Pelos critérios dos autores - autonomia dos jornalistas frente aos poderes econômico e político, representatividade das associações profissionais em relação ao conjunto dos jornalistas, capacidade das associações em elaborar e fazer respeitar um código de conduta profissional 
- o nível de profissionalismo do jornalismo brasileiro parece muito baixo. Com relação à autonomia frente às forças politicas, em especial, basta dizer que os jornalistas brasileiros adotaram como sua a definição da profissão fornecida pelo decreto-lei $n^{\circ} 972$, imposto à sociedade pelo regime militar com base no Ato Institucional $\mathrm{n}^{\circ} 5$.

Quanto à atuação das associaçôes no que se refere aos códigos de conduta profissional, deve-se reconhecer que um código de ética está em vigor no país desde 1987, e que ele é bastante detalhista em seus princípios. Contudo, a sua leitura deixa a nítida impressão de que o código foi elaborado com base em uma definição bastante restrita de jornalismo, que se aplica fundamentalmente aos grandes jornais do pais e deixa a descoberto o significativo conjunto de atividades que, por força do decreto-lei e dos interesses corporativos das associações, foram reconhecidas como tendo caráter jornalístico. $\mathrm{O}$ artigo primeiro, por exemplo, reza que "o acesso à informação pública é um direito inerente à condição de vida em sociedade, que não pode ser impedido por nenhum tipo de interesse". Não é dificil perceber que sua aplicação ao universo das assessorias de imprensa é bastante complicada, visto que neste caso o interesse do cliente contratante é a razão de ser do trabalho, e ele não necessariamente coincide com o interesse público. $\mathrm{O}$ item $\mathrm{b}$ do artigo 13, por outro lado, estabelece que o jornalista "deve evitar a divulgação de fatos mórbidos e contrários aos valores humanos". Ora, esta é a própria substância do sensacionalismo, matéria prima de muitos jornais "populares" do país (e presente também nos grandes jornais).

Esses dois exemplos bastam para demonstrar que o código de ética dos jornalistas provê um modelo utópico de conduta, antes que fornece orientação para questões concretas da prática profissional. Deste modo, ele mantém uma relação distante com uma efetiva discussão sobre a identidade jornalistica no país. O decreto-lei $\mathrm{n}^{\circ} 972$ parece ter atuado no sentido de deslocar esta questão para o segundo plano. Não por coincidência, os periodos em que a obrigatoriedade do diploma específico esteve em questão - na década de 1980, por ocasião da redemocratização e dos debates relativos à elaboração da nova constituição, e entre 2001 e 2005, quando uma série de decisões judiciais suspendeu provisoriamente a obrigatoriedade do diploma - estimularam fortemente o debate sobre a identidade jornalística no Brasil ${ }^{12}$.

Ao fornecer uma resposta meramente formal para a questão da identidade jomalistica, o decreto-lei 972 tem frustrado o desenvolvimento mais consistente do jornalismo como comunidade interpretativa no Brasil e, como conseqüência, tem servido de obstáculo para o desenvolvimento de meios eficazes de auto-regulamentação por parte dos jornalistas brasileiros.

${ }^{12}$ Uma pequena amostra dos debates promovidos na década de 1980 sobre o tema podem ser encontradas em Medina (1987). Quanto ao debate mais recente, ele foi objeto de análise de Fortes e Albuquerque (2004). 
A ausência de um debate mais consistente sobre a questão da identidade jornalística revela todos os seus problemas em um momento em que o jornalismo enfrenta múltiplos desafios. Respostas fornecidas em um momento anterior simplesmente não parecem mais fazer sentido diante de novas questões que se apresentaram recentemente. Um exemplo diz respeito às questões que surgiram em torno do fenômeno do jornalismo digital. Em um artigo muito interessante, Adghirni (2001) destacou os problemas que o meio digital apresentou para a identidade do jornalista: estaria a sua identidade se confundindo com a de "produtor de conteúdo"? Um dos aspectos do problema é o fato de a definição formulada pelo decreto-lei $\mathrm{n}^{\circ} 972$ não contemplar o jornalismo realizado na internet: "O Sindicado de Jornalistas do DF recebe regularmente denúncias contra os 'invasores da profissão'. Que fazer? Por enquanto nada, responde o presidente do Sindicato, Edgar Tavares, já que não existe regulamentação definida para o jornalismo na internet" (Adghirni, 2001: 138). Em um trecho, logo a seguir, a autora afirma que "o Sindicato não tem como averiguar quantos não-jornalistas estão empregados nos pequenos sites e portais efêmeros que proliferam na internet" (2001: 139).

Tais observações ilustram, de forma cabal, os argumentos que desenvolvemos neste artigo: ao invés de estimular o debate e problematizar as fronteiras que definem a identidade jornalística, as associações profissionais de jornalistas optaram pela solução corporativista da defesa e ampliação dos privilégios estabelecidos pelo decreto-lei $\mathrm{n}^{\circ} 972$, sem se preocupar se eles 88 têm condições de se sustentar na situação presente. Ao procederem assim, eles requentam velhas respostas, elaboradas a partir de questões totalmente diferentes das que se apresentam atualmente e perdem a oportunidade de discutir o futuro do jornalismo.

\section{Referências Bibliográficas}

Abramo, Cláudio (1988). A regra do jogo. São Paulo: Companhia das Letras. Abreu, Alzira Alves de (1998). Jornalistas: de românticos a profissionais. Antropolítica n. 5, p. 7-19.

Abreu, Alzira Alves de (2003). "Jornalistas e jornalismo econômico na transição democrática". In Alzira Alves de Abreu et al. Midia e Política no Brasil: Jornalismo e Ficção. Rio de Janeiro: FGV Editora.

Adghirni, Zélia Leal (2001). Informação on-line: jornalista ou produtor de conteúdos? Contracampo: Revista do Mestrado em Comunicação, Imagem e Informação, 6, p. 137-151. 
Adghirni, Zélia Leal (2004). Hibridação e gêneros midiáticos: a informação jornalistica mediada pelas instituições de comunicação. Ícone. Programa de Pós-Graduação em Comunicação/UFPE 7: 140-152.

Agee, Warren K. \& Nelson Traquina (s.d.) O Quarto Poder Frustrado: os meios de comunicação social pós-revolucionário. Lisboa: Vega.

Albuquerque, Afonso de (2005). Another 'Fourth Branch': press and political culture in Brazil. Journalism 6 (4): 486-504.

Andrade, Evandro Carlos de (2003). "Entrevista a Alzira Alves de Abreu e Fernando Lattman-Weltman", publicada em Alzira Alves de Abreu, Fernando Lattman-Weltman \& Dora Rocha. Eles mudaram a imprensa: depoimentos ao CPDOC. Rio de Janeiro: FGV Editora.

Blanchard, Margareth A. (1986). Exporting the First Amendment. The PressGovernment Crusade of 1945-1952. New York: Longman.

Braga, José Luiz (1991). O Pasquime os anos 70: mais pra epa que pra oba... Brasilia: Ed. UNB.

Burgh, Hugo de (2003). Skills are not enough. The case for journalism as an academic discipline. Journalism 4 (1): 95-112.

Chalaby, Jean K. Journalism as an Anglo-American Invention: A Comparison of the Development of French and Anglo-American Journalism, 1830s-1920s. European Journal of Communication, vol. 11 (3), 1996, p. 303-326.

Dines, Alberto. Um Oscar para Veja: o macartismo mainardiano em ação. Observatório da Imprensa n ${ }^{\circ} 357$, postado em 5/12/2005. Capturado em 9/2/ 2006 no endereço eletrônico http://observatorio. ultimosegundo.ig.com.br/ artigos. asp?cod=357JDB006

Ettema, James S. \& Theodore L. Glasser (1998). Custodians of Conscience: Investigative Journalism and Public Virtue. New York: Columbia University Press.

Fish, Stanley (1980). Is There a Text in this Class? The Authority of Interpretative Communities. Cambridge (Mass.) \& London. Harvard University Press.

Fortes, Rafael \& Afonso de Albuquerque (2004). O jornalismo e o diploma: negociando as fronteiras da comunidade jornalística no Brasil. Texto apresentado no XXVII Congresso Brasileiro de Ciências da Comunicação, Porto Alegre. 
Hallin, Daniel C. (1996). "Comercialism and Professionalism in the American News Media". In James Curran \& Michael Gurevitch (eds.). Mass Media and Society. London: Arnold, $2^{\text {nd }}$ ed.

Hallin, Daniel C. \& Paolo Mancini (2004). Comparing Media Systems: Three Models of Media and Politics. Cambridge: Cambridge University Press.

Hallin, Daniel C. \& Stylianos Papathanassopoulos (2002). Political Clientelism and the Media: Southern Europe and Latin America in comparative perspective. Media, Culture \& Society, 24(2) p. 175-195.

Köcher, Renate (1986). Bloodhounds or Missionaries: Role Definitions of German and British Journalists. European Journal of Communication 1 (1): 43-64

Kucinski, Bernardo (1991). Jornalistas e revolucionários: nos tempos da imprensa alternativa. São Paulo: Página Aberta.

Laurenza, Ana Maria de Abreu (1998). Lacerda $x$ Wainer: o Corvo e o Bessarabiano. São Paulo: Editora Senac.

Lopes, Boanerges e Roberto Fonseca Vieira (2004). Jornalismo e Relações Públicas: Ação e Reação. Uma Perspectiva Conciliatória Possível. Rio de Janeiro, Mauad Editora.

Markun, Paulo (2005). Meu querido Vlado: a história de Vladimir Herzog e do sonho de uma geração. Rio de Janeiro: Objetiva

Medina, Cremilda (1987). O jornalismo na Nova República. São Paulo: Summus Editorial.

Neveu, Eric (2003). Sociologia do Jornalismo. Porto: Porto Editora.

Pinto, Manuel (2004). O ensino e a formação na área do jornalismo em Portugal: crise de crescimento e notas programáticas. Comunicação e Sociedade (UM) 5: 49-62

Ribeiro, Ana Paula Goulart. "Memória de Jornalista: Um Estudo sobre o Conceito de Objetividade nos Relatos dos Homens de Imprensa nos Anos 50" (2003). In Vera França, Maria Helena Weber, Raquel Paiva \& Liv Sovik (org.). Estudos de Comunicação - XI Compós. Porto Alegre: Sulina.

Ruellan, Denis (2004 a). A roupa justa do jornalista: o estatuto profissional à prova da jurisprudência. Texto apresentado no XII Encontro Anual da Associação Nacional de Programas de Pós Graduação em Comunicação (COMPÓS). São Bernardo do Campo (SP).

Ruellan, Denis (2004 b). Grupo profissional e mercado de trabalho do jornalismo. Comunicação e Sociedade (UM) 5: 9-24. 
Sá, Adílsia (1999). O jornalista brasileiro (Federação Nacional dos Jornalistas Profissionais, de 1946 a 1999). Fortaleza: Fundação Demócrito Rocha.

Silva, Carlos Eduardo Lins da (1988). Mil dias: os bastidores da revolução em um grande jornal. São Paulo: Trajetória cultural.

Silva, Carlos Eduardo Lins da (1991). O adiantado da hora: a influência americana sobre o jornalismo brasileiro. São Paulo: Summus.

Smith, Anne-Marie (2000). Um acordo forçado. O consentimento da imprensa à censura no Brasil. Rio de Janeiro, Editora FGV.

Soifer, Aviam (1985). "Freedom of the Press in the United States". In LAHAV, Pnina (ed.). Press Law in Modern Democracies. New York: Longman, 1985, p. 79-133.

Wainer, Samuel (2000). Minha Razão de Viver: Memórias de um Repórter. Rio de Janeiro, Record, $17^{\mathrm{a}}$ ed.

Weber, Maria Helena (2000). Comunicação e Espetáculos da Politica. Porto Alegre: Editora da Universidade/UFGRS.

Zelizer, Barbie (1992 a). Covering the Body: the Kennedy Assassination, the Media, and the Shaping of Collective Memory. Chicago and London: The University of Chicago Press, 1992.

Zelizer, Barbie (1992 b). CNN, the Gulf War, and journalistic practice. Journal of Communication 42 (1), p. 66-81.

Zelizer, Barbie (2004). Taking Journalism Seriously: News and the Academy. Thousand Oaks, London and New Delhi: Sage Publications. 
Eontracampo"

92 